\title{
Increasing Educational Disparities in the Timing of Motherhood in the Andean Region: A Cohort Perspective
}

\author{
Ewa Batyra ${ }^{1,2}$ (D) \\ Received: 14 May 2018 / Accepted: 7 June 2019 / Published online: 12 July 2019 \\ (C) The Author(s) 2019
}

\begin{abstract}
In spite of a peculiar pattern of the age at first birth in Latin America, there is little research about the long-term trends in the timing of transition to motherhood at all stages of women's reproductive lives and across countries in the region. This paper examines the evolution of educational disparities in the age at first birth during the fertility transition in three Andean region countries: Ecuador, Colombia, and Peru. Using birth history information available in the latest Population and Housing Censuses, I estimate the first-birth age-specific rates disaggregated by various measures of education level, for cohorts born between 1945 and 1980. In all countries, educational expansion was accompanied by increasing rates of first birth before the age of 20 among women with below completed higher education, but the most drastic change occurred among women who dropped out of secondary school. Concurrently, the first-birth rates at the age of 20-29 decreased for women who achieved higher education; an evidence of an increase in the rates above the age of 30 among them started to emerge. A pronounced divergence in the first-birth timing between the educational groups occurred during the fertility transition. Comparison of a relative and an absolute educational level classification shows that the increasing disparities between the lowest and the highest educated women were similarly pronounced even when accounting for the changes in educational composition across cohorts. This paper discusses the potential factors behind the polarization in the age at first birth in the region. It argues that there is a need for policies encouraging not only secondary school entrance but also secondary school completion in the context of substantial educational expansion and high levels of school dropout observed in the region.
\end{abstract}

Keywords Timing of motherhood $\cdot$ Fertility transition $\cdot$ Education $\cdot$ Latin America Census data

Ewa Batyra

e.batyra@1se.ac.uk; batyra@sas.upenn.edu

Extended author information available on the last page of the article 


\section{Introduction}

The changes in the timing of motherhood in Latin America received considerable attention due to increases in teenage fertility in the region (Rodríguez 2013; Rodríguez Vignoli 2014a, b). However, beyond adolescent motherhood, relatively little is known about the long-term trends in the age of first birth. In particular, the variation in these trends by measures of socioeconomic status between the countries in the region and throughout the fertility transition remains underexplored.

Examining these processes is particularly relevant for Latin America. The region is characterized by stark inequalities in economies, labor markets, and between social strata. These inequalities are reflected in different patterns of reproductive behavior between population groups (ECLAC 2011). Moreover, there has been growing evidence of increasing polarization in the first birth timing within a number of Latin American countries, attributed to substantial differences in the age of childbearing between the lowest and the highest educated population strata (Lima et al. 2018). However, limited evidence exists about the changes in the educational disparities in the timing of motherhood during Latin American fertility transition. So far, the geographical scope of these studies has been limited to single-country analysis of settings with the lowest levels of total fertility rate (TFR). Research on Brazil (Miranda-Ribeiro and Garcia 2013; RiosNeto et al. 2018) and Uruguay (Nathan 2015) identified increasing educational disparities in the timing of transition to first birth. This process was driven by the advancement of motherhood among low educated and the emerging first birth postponement among the highest educated women. While in other Latin American countries acceleration of the entrance into motherhood among low educated women has been previously examined in the studies on teenage childbearing (e.g., Esteve and Florez-Paredes 2014, 2018; Rodríguez Vignoli and Cavenaghi 2013), the topic of changes in the rates of first birth at older ages and motherhood postponement attracted little research attention.

Andean region is one of the settings where transition to first birth has been so far examined primarily from the perspective of changes in adolescent childbearing. This approach can be seen as limited—changes in the timing of motherhood can be reflected in the increases or decreases in the rates of first birth not only at the youngest, but also at older ages. The detailed knowledge about the long-term changes in the pattern of childbearing timing requires examination of the first birth rates across the entire reproductive life course.

The objective of this study is to examine the long-term cohort trends in the educational differences in the age at first birth during the fertility transition in three Andean region countries: Colombia, Ecuador, and Peru. I examine the changes in the age of entrance into motherhood and the variation in this process by education level in a holistic way by estimating the first-birth age-specific rates for cohorts of women born between 1945 and 1980. For that purpose, the question about the age at first birth, available in the latest Population and Housing Census for each of these three countries, is used. This piece of information has not been previously utilized to study timing of childbearing in Colombia, Peru, 
or Ecuador. Due to larger sizes as compared to available surveys, such as Demographic and Health Survey (DHS), census data make it possible to explore two previously understudied aspects of the timing of motherhood in the Andean region. First, they can be used to estimate the first-birth age-specific schedules, providing a complete picture of changes in the timing of childbearing. Second, using census data one can explore more detailed educational level classifications, casting light on the factors behind the changing educational disparities in the age at first birth. In this paper, the focus is on two aspects of the relationship between education level and timing of transition to motherhood.

First, I examine the changing differences in the age at first birth between the lowest and the highest educated women in the three countries. I explore the extent to which these differences have been changing not only due to motherhood advancement among low educated women, but also whether there are signs of motherhood postponement among women with the highest levels of schooling. For that purpose, I study the behavior of women who completed university - a small but growing population stratum in the Andean region countries. Subsequently, I explore the role of the changing educational composition in the process of changing educational differences in the first-birth timing between the lowest and the highest educated. For that purpose, I classify women according to their educational attainment, as well as a measure that takes into account changes in the educational composition across cohorts, and I compare the results.

Second, I study the variation in the pattern of first birth among women with intermediate levels of education. As mentioned above, the prominence of the educational differences in the age at first birth between the lowest and the highest educated in Latin America has been highlighted in previous research. On the other hand, the understanding of the variation in the pattern of motherhood timing among women with intermediate levels of schooling, in particular those who enter secondary school is limited. In this paper, I distinguish between, and compare, women who complete and dropout of secondary school. This analysis aims to enhance the understanding of the changing educational disparities in the timing of motherhood in the context of substantial increase in the share of women who enter secondary school and high levels of secondary school dropout observed in the region (Kattan and Székely 2015).

\section{Context of the Andean Region: Ecuador, Peru, and Colombia}

Ecuador, Colombia, and Peru are characterized by high levels of social and economic inequalities. Between the 1950s and 2000s, these countries experienced periods of increasing income inequalities, in particular during the recession of the 1980s (Cornia 2014). What distinguishes Andean region from the other parts of Latin America is a substantial percentage of the population of indigenous origin who are more likely than non-indigenous groups to belong to poorer households, receive less schooling, and live in the rural parts of the countries (World Bank 2015). Moreover, a characteristic of the three countries is a challenging geography, which determines substantial social and economic inequalities between 
regions and urban-rural areas. These marked inequalities in Ecuador, Peru, and Colombia are reflected in different patterns of reproductive behavior between the population strata.

Education has been one of the most important markers of the differences in fertility and timing of motherhood in the Andean region and Latin America more broadly (Bozon et al. 2009; Castro-Martín and Juarez 1995; ECLAC 2011; Heaton and Forste 2009; Rodríguez 2013; Weinberger et al. 1989) but these processes have been also differentiated by household income, ethnicity, and place of residence (Davis et al. 2015; ECLAC 2005, 2011; Rodríguez Vignoli 2014b). There exists a strong association between all of these characteristics in Colombia, Ecuador, and Peru. In particular, the income, regional and ethnic inequalities are reflected in inequalities in access to education and student performance. In order to understand the changing differences in the timing of motherhood by educational level, it is important to consider the factors behind the educational inequalities observed in the region.

First, due to increasing coverage since the 1950s, children from poorer households who were previously excluded from the educational system have been increasingly entering and completing primary and secondary school education (Bassi et al. 2015; ECLAC 2010). However, this educational expansion, as well as the demographic growth of children and adolescence during the twentieth century, put a strain on the educational systems and influenced the quality of teaching which varies largely by school and by place of residence. The schools tend to be highly segregated by socioeconomic class (Murillo and Martínez-Garrido 2017), which has been suggested to be related to the problem of perpetuation of inequality (Carlson 2001; Daude 2013; ECLAC 2010).

Second, although children from the more disadvantaged backgrounds have been increasingly starting secondary school, the completion rates among them are lower than among those among wealthier socioeconomic groups. The educational expansion resulted in virtually universal primary school coverage in the three countries, but the secondary school attendance and completion rates have been lower (ECLAC 2010). The problem of secondary school grade repetition and dropout in the region has been particularly pronounced (Kattan and Székely 2015) and is more common among the poorer, those living in rural areas and indigenous populations (ECLAC 2002, 2007, 2010). Moreover, completing university in that context is still something that is reserved for more privileged groups. In all three countries, there is a wide range of private and public universities. These have varying tuition fees, which at some institutions depend on the income of students' parents. However, the completion of a low quality secondary school education can limit the chances of students from poorer backgrounds to attend university (ECLAC 2010). The poor quality of secondary schools can contribute not only to lower chances of attending university, but also lower aspirations and incentives to complete secondary school at all (Kattan and Székely 2015). 


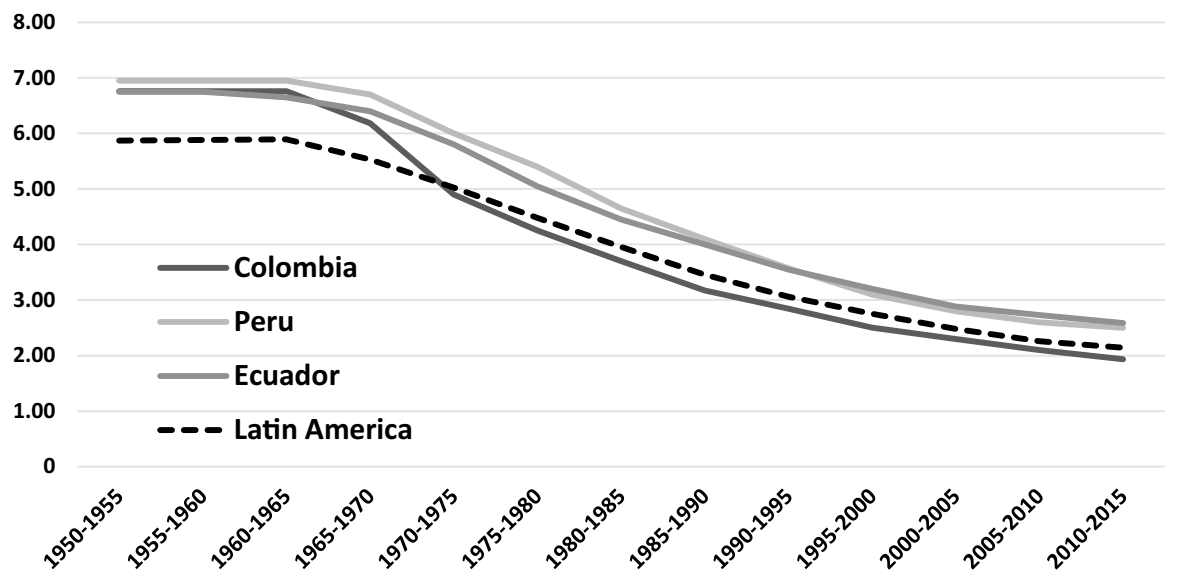

Fig. 1 Trends in total fertility rate in Colombia, Peru, Ecuador, and Latin America, 1950-2015. Source United Nations (2017)

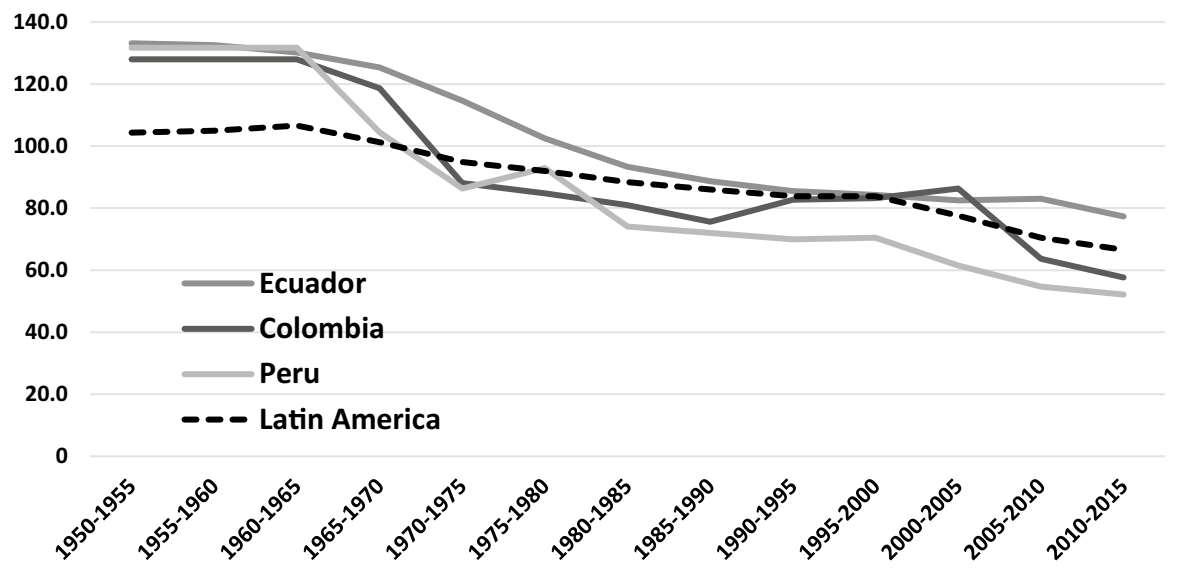

Fig. 2 Trends in fertility rate at age 15-19 in Colombia, Peru, Ecuador, and Latin America, 1950-2015. Source United Nations (2017)

\section{Fertility and Timing of Motherhood in Colombia, Ecuador and Peru}

The TFRs in Ecuador, Peru, and Colombia declined in the last half of the century to the level close to replacement (from the level of almost 7 in 1950 to 1.9 in Colombia, 2.5 in Peru, and 2.6 in Ecuador in 2010-2015, shown in Fig. 1) (United Nations 2017). The TFR decline in the three countries started later and from a higher level than in other parts of the continent, for example countries of the Southern Cone. Although the initial levels were similar to those of Brazil, the change proceeded there at a slower rate (Chackiel and Schkolnik 1996). 
Studies about the timing of childbearing by education level in Ecuador, Peru, and Colombia have concentrated on exploring trends in and determinants of adolescent motherhood. In spite of the continuously declining TFRs, plateauing or increases in teenage fertility rates (age-specific fertility rate at age 15-19) ${ }^{1}$ occurred during the 1990s (Fig. 2). The turn to earlier motherhood was most pronounced among women with the lower and middle levels of education (Bozon et al. 2009; Esteve and FlorezParedes 2014, 2018; Rodríguez 2013; Rodríguez Vignoli and Cavenaghi 2013).

A number of explanations has been suggested for the high or at time increasing levels of teenage births which are mainly unintended (Measure DHS 2018). Some studies pointed to the importance of the continued barriers to fertility regulation among young, less advantaged women, such as limited access to contraception and sexual and reproductive health services (Rodríguez Vignoli 2017). The issues around insufficient sexual education, a taboo culture around the sexuality of teenagers as well as a limited bargaining power to negotiate condom use among adolescents were also put forward as possible explanations (Rodríguez 2013; Rodríguez Vignoli and Cavenaghi 2013).

Other research points to high levels of social and economic inequalities which characterize Latin America in general as contributing to the exceptionally high rates of adolescent motherhood (Azevedo et al. 2012). Studies suggest that the observed increase in early motherhood in the region was driven by poverty and the low opportunity cost of early motherhood among less educated women. That is, those who completed few years at school advanced motherhood due to their limited social mobility perspectives and employment prospects (Flórez 2005; Flórez and Soto 2007; Gaviria 2000). Rodríguez Vignoli and Cavenaghi (2013) showed that in a number of Latin American countries, including Ecuador, teenage motherhood increased between 1990 and 2010 among not only the lower educated, but the change was also pronounced among women with intermediate levels of schooling. Due to the educational expansion, the educational threshold for obtaining employment has likely risen over time, contributing to the limited opportunities on the labor market and an early family formation pattern even among those who attended secondary school.

In spite of the fact that teenage fertility rates remain high in the three countries, since the 2000s the increase in the ASFRs at age 15-19 reversed in Colombia; the rates started to decline again in Ecuador and Peru (Fig. 2). These teenage fertility declines coincided with increases in the percentage of women still childless in their mid-20 s across Latin American countries, pointing to the emergence of motherhood postponement. This process was particularly pronounced among the highest educated women (Rosero-Bixby, Castro-Martín, and Martín-García 2009). Moreover, a study for Colombia has shown that the risk of first birth decreased across recent cohorts of women who entered higher education, suggesting a retreat from early childbearing in that educational stratum (Batyra 2016). In spite of these emerging changes, so far, the evolution of the pattern of transition to first birth at all stages of women's

\footnotetext{
1 Due to the substnatial reductions in fertility levels, the fertility rates in all other age groups has been declining in the three countries throughout the fertility transition (United Nations 2017).
} 
reproductive lives and the differences in this pattern between educational groups has not attracted research attention in the context of the Andean region more broadly.

\section{Objectives and Hypotheses}

The objective of this paper is to examine trends in the educational differences in the age at first birth in Colombia, Ecuador, and Peru during the fertility transition. I study cohorts of women born starting from 1945 who were entering their reproductive lives at the beginning of the fertility transition in the 1960s. I examine how the rates of first birth have been changing across cohorts, across all stages of women's reproductive lives and disaggregate these trends by education level. Basing on the literature presented in the previous sections, this paper focuses on exploring two aspects of educational disparities in the age at first birth.

First, I study in depth the changing differences in the rates of first birth between the lowest and the highest educated women. As explained in the previous section, the advancement of motherhood among the lowest educated women in Colombia, Ecuador, and Peru has been widely acknowledged. On the other hand, due to the scarcity of research about the rates of transition to first birth beyond the age of 20 , to what extent, if any, highly educated women have been postponing motherhood is less clear, in particular in the case of Ecuador and Peru. Given the identified emergence of motherhood postponement among women who entered university in Colombia (Batyra 2016), I hypothesize that similar process has been taking place in Peru and Ecuador. In the analyses, I examine the behavior of a subgroup of women that is likely to be postponing motherhood to the largest extent-women who completed higher education. Completion of university has been argued to be strongly related to first-birth postponement across various settings (Mills et al. 2011). In this study, looking at the behavior of women who complete university is possible thanks to the use of census data, which allow for a more detailed education level classification than available for the Andean region survey data.

In the next step, I cast light on the role of the changes in the educational composition of the cohorts in the process of changing differences in the motherhood timing between the highest and the lowest educated women. Due to the educational expansion, women with the fewest years of education in younger cohorts in Latin America could have become a shrinking group, likely belonging to the poorest population strata (Rodríguez Vignoli and Cavenaghi 2013). Therefore, I hypothesize that the observed advancement of motherhood among women with the lowest educational attainment in the younger cohorts is to some extent driven by the fact that they have become an adversely select group. Consequently, the changing educational composition of cohorts might be responsible to a certain degree for the changing disparities in the age at first birth between the lowest and the highest educated women.

In order to explore this aspect, I use and compare two measures describing the level of education: (i) women's educational attainment and (ii) women's relative position within a cohort in terms of educational achievement-a measure that varies depending on the educational composition of a given cohort. Previous research has shown that the changes over time within educational groups in various demographic 
processes such as life expectancy (Bound et al. 2015) or teenage motherhood (Esteve and Florez-Paredes 2014, 2018) might be attenuated when using a relative education classification, as compared to the fixed educational categories. In particular, based on DHS data for a number of Latin American countries, Esteve and Florez-Paredes (2018) concluded that changes in the adolescent first-birth rates within the lowest and the medium educational strata have been more stable across cohorts when examined using the relative education classification. They argued that when the relative educational classification was used, the less educated women across cohorts exhibited a stability in the rates of first birth before the age of 18. In this study, using census data, I focus on examining the extent to which the trends in the disparities in the rates of first birth between the lowest and the highest educated strata will differ when using the relative educational classification and the classifications describing women's educational attainment, at all ages. If these are of a similar direction and magnitude, it will be an indication that the changing first-birth pathways between the lowest and the highest educated have not been driven by the changing educational composition of the population.

Second, I explore the trends in the first-birth rates of women with intermediate level of schooling, focusing on the variation in the timing of transition to motherhood within that educational group. Due to educational expansion in Latin American countries in the last decades, there occurred substantial changes in the educational composition of the population and a vast increase in the share of women who enter secondary school (Rios-Neto and Meireles Guimarães 2014). Yet the variation in the pattern of the age at first birth within the group of women who enter secondary school has not been previously explored. In this paper, I hypothesize that this population stratum has been becoming increasingly heterogeneous. To explore this issue I examine the trends and the differences in the rates of first birth between women who completed and dropped out of secondary school. As described in "Context of the Andean region: Ecuador, Peru and Colombia" section, the non-completion of secondary education is a crucial problem. However, changes in the timing of motherhood of women who enter but do not finish secondary school has not been previously examined. This analysis provides a new dimension to the understanding of the fertility behavior of the intermediate educated women in the region.

\section{Data and Methods}

This study uses the Population and Housing Censuses for Ecuador (2010), Peru (2007), and Colombia (2005). It encompasses countries of the Andean region for which the information about the timing of first birth is available. The main variable of interest in this study is the age or year in which women aged $12+$ had their first birth.

In the censuses for Ecuador and Peru, women were asked about their age at first birth; in Colombia, the question was about the year of first birth. In order to obtain the information about the age at first birth, I subtracted the year of each woman's first birth from the year of the census. I classified women into yearly 
birth cohorts using the variable describing women's year of birth for Ecuador and Colombia. Due to the unavailability of this information for Peru, I calculated women's year of birth by subtracting their age from the year of the census. I studied cohorts born between 1945 and 1980. The analysis is confided to women born until 1980, since in all of the countries they were at least 25 years old. It is reasonable to assume that the level of education does not considerably change beyond that age, since the typical age of graduation from university in all three countries is below the age of 25. This allows for a consistent comparison of the trends by education level between the cohorts and countries.

To study the changes in the age at first birth, from each census I calculated the first-birth age-specific rates, separately for each birth cohort. These rates are calculated using a life table approach and are obtained by dividing the number of first births which occurred in a given age interval, by the number of women at risk of first birth at the beginning of that age interval and the length of the interval. Consequently, in the denominator, these rates include women in a particular cohort who were still childless at a given age. Such calculated rates correspond to the hazard of first birth, which is the probability of first birth in a given age group among women at risk of first birth, divided by the width of the age interval. This approach allows studying changes in the rates of transition to motherhood over women's reproductive lives and across cohorts.

The first-birth rates are calculated for grouped age intervals. First, the firstbirth age-specific schedules are presented for the 5-year age groups. This approach is conventionally applied when estimating the age-specific fertility rates and is used also in this study to calculate of the first-birth age-specific rates. Next, to examine in detail the changing disparities in the timing of transition to motherhood between the educational groups throughout the fertility transition, I present trends in the first-birth rates across cohorts in three age intervals: 10-19, 20-29, and 30-39. This grouping allows unveiling the broad patterns in the first birth advancement and postponement-two processes that are expected to be contributing to the changing differences in the timing of transition to motherhood between the educational groups. The advancement of motherhood is expected to be reflected in the increasing rates of first birth below the age of 20 . The changes in the rates of first birth during women's $20 \mathrm{~s}$ (initial decreases in the rates of first birth) and $30 \mathrm{~s}$ (subsequent increases in the rates of first birth) are expected to be reflecting the extent of motherhood postponement. The first-birth rates are calculated for one-year birth cohorts. To facilitate the presentation and the interpretation of the results, for each cohort, the final rates are shown as the local average of the estimate for that cohort and the four nearest birth cohorts. For example, the rate of first birth at age 20-24 for the 1950 cohort is the average of the rates for that age group for cohorts of women born between 1948 and 1952. I calculated these rates for the total population and for educational groups.

I classified women according to the stages of each country's educational system. This allows for the examination of how the timing of transition to motherhood has been changing within the actual educational strata. This is important in order to interpret the findings within the context of the educational expansions observed 
Table 1 Relative educational level classification for the 1945 and the 1980 cohort, number of years of schooling, first quartile (Q1) and fourth quartile (Q4), Ecuador, Colombia, and Peru. Source Author's calculations from Population and Housing Censuses Colombia 2005, Peru 2007, Ecuador 2010

\begin{tabular}{lllllllll}
\hline Cohort/quartile & \multicolumn{2}{l}{ Ecuador } & & & \multicolumn{2}{l}{ Colombia } & & \multicolumn{2}{l}{ Peru } & \\
\cline { 2 - 3 } & Q1 & Q4 & & Q1 & Q4 & & Q1 & Q4 \\
\hline 1980 & $0-6$ & $14+$ & & $0-6$ & $13+$ & & $0-7$ & $15+$ \\
1945 & $0-1$ & $6+$ & & $0-2$ & $7+$ & $0-1$ & $11+$ \\
\hline
\end{tabular}

in the three countries. The main analysis in this paper entails dividing women into four categories: (i) up to completed primary school, (ii) incomplete secondary school, (iii) completed secondary school, ${ }^{2}$ and (iv) completed higher education. Primary school lasts 5 years in Colombia, 6 years in Peru and Ecuador. It takes 6 years to complete secondary school in Colombia and Ecuador; 5 years in Peru. I divided women who entered secondary school into those who completed it and those who did not. Women who entered secondary school but completed fewer years than equivalent to the length of the secondary school, are referred as women who dropped out of secondary school (group ii-incomplete secondary). The limitation of this study is that women's level of education reported in the censuses relates to that at the time of the interview, and not at the time of first birth. Therefore, it is not possible to identify at what age women completed a given level of education or left school. This means that it is not feasible to determine whether women dropped out of secondary school before or after their first birth, which is an aspect discussed in detail in the conclusions. I classified women as having attained higher education if they completed a number of years of schooling necessary to obtain the qualification Superior. In these countries, it usually amounts to between 3 and 5 years, depending on the type of the programme.

In the next step, I conducted the analysis using the educational classification that describes women's relative position within a cohort in terms of educational achievement. I calculated the top and the bottom quartiles of the educational attainment distribution for each cohort. I used a variable describing the level of education attained and the number of years of schooling completed. Table 1 shows the number of years of schooling which fall into each of the relative educational level categories across the three countries for the youngest (1945) and the oldest (1980) cohort. This shows that the educational composition of the population shifted substantially upwards. Broadly speaking, for the youngest cohort, having achieved a number of years of

\footnotetext{
2 This educational group includes both women who completed secondary school only and women who entered but did not complete higher education. Such classification is used as the higher education dropout in Latin America is concentrated at the beginning of the college career (Ferreyra et al. 2017). Therefore, women who entered but did not complete higher education are likely to be more similar in their behavior to those who completed secondary school only, as compared to women who completed higher education. This is confirmed by additional analysis (not shown). Importantly, the completion of university has been argued to be strongly related to the timing of transition to motherhood, in particular firstbirth postponement (Mills et al. 2011). For these reasons, in this study women who dropped out of university are grouped together with women who completed secondary school only, and are not combined with women who completed university.
} 
Table 2 Ethnic composition of the educational groups for the 1945 and the 1980 cohort (\% of the female population by ethnicity within each of the educational stratum), Ecuador and Colombia. Source Author's calculations from Population and Housing Censuses Colombia 2005, Ecuador 2010

\begin{tabular}{|c|c|c|c|c|c|c|c|}
\hline \multirow[t]{2}{*}{ Education } & \multirow[t]{2}{*}{ Ethnicity/cohort } & \multicolumn{3}{|l|}{ Ecuador } & \multicolumn{3}{|l|}{ Colombia } \\
\hline & & Indigenous & Black & Other & Indigenous & Black & Other \\
\hline \multirow[t]{2}{*}{ Up to completed primary } & 1945 & 9.5 & 5.9 & 84.6 & 3.4 & 9.5 & 87.1 \\
\hline & 1980 & 13.6 & 8.7 & 77.7 & 8.0 & 13.0 & 79.0 \\
\hline \multirow[t]{2}{*}{ Incomplete secondary } & 1945 & 0.8 & 4.9 & 94.3 & 0.6 & 6.9 & 92.5 \\
\hline & 1980 & 4.0 & 11.5 & 84.5 & 2.0 & 12.5 & 85.6 \\
\hline \multirow[t]{2}{*}{ Completed secondary } & 1945 & 0.3 & 2.7 & 97.0 & 0.6 & 4.7 & 94.7 \\
\hline & 1980 & 2.5 & 6.8 & 90.7 & 1.3 & 10.8 & 88.0 \\
\hline \multirow[t]{2}{*}{ Completed higher } & 1945 & 0.2 & 3.0 & 96.8 & 0.4 & 5.2 & 94.4 \\
\hline & 1980 & 1.1 & 3.9 & 95.1 & 0.7 & 7.6 & 91.8 \\
\hline \multirow[t]{2}{*}{ Total } & 1945 & 7.6 & 5.4 & 87.0 & 3.0 & 8.3 & 88.7 \\
\hline & 1980 & 6.5 & 7.9 & 85.6 & 3.0 & 11.1 & 85.9 \\
\hline
\end{tabular}

schooling equivalent to the completion of primary education ( 5 or 6 years depending on the country) meant being at the bottom of the educational distribution. For the older cohorts, it was enough to complete just beyond 1 or 2 years at school to belong to the population stratum with a more advanced educational level. In fact, in Ecuador and Colombia it was roughly enough to complete primary school to be at the top of the educational distribution. This suggests that, in all countries, women who do not go beyond primary education in the younger cohorts are becoming a shrinking population group, likely from the lowest socioeconomic strata.

Censuses do not include information about socioeconomic status, such as income, that could cast light on the changes in the socioeconomic composition of the population in each of the educational groups. Nonetheless, censuses for Colombia and Ecuador include information about ethnicity, which is associated with socioeconomic status in the Andean region. As explained in "Context of the Andean region: Ecuador, Peru and Colombia" section, there exist a strong relationship between income, ethnicity, and place of residence. Looking at the changes in the ethnic composition of the educational groups can cast some light on the changing socioeconomic composition of each of the educational stratum (Table 2). I show the results for Colombia and Ecuador only as the Peruvian census did not ask about ethnicity. For comparability between the two countries, I grouped women into three broad categories: Indigenous, Black, and Other. ${ }^{3}$

\footnotetext{
3 In Colombia, six ethnic groups were distinguished in the census: (i) Indigenous, (ii) Black, Mulatto, African-Colombian or of African descent, (iii) Rom, (iv) Raizal of the Archipelago of San Andrés and Providencia, (v) Palenquero of San Basilio and (vi) none of the above. In Ecuador 8 ethnic groups were distinguished: (i) Indigenous, (ii) Afro-Ecuadorian or of African descent, (iii) Black, (iv) Mulatto, (v) Montubio, (vi) Mestizo,(vii) White and (viii) Other. In both countries, women who identified themselves as Indigenous were classified in this study as "Indigenous"; women who classified themselves as Black, Mulatto, of African descent, Afro-Colombian or Afro-Ecuadorian were grouped into one category "Black". The rest of women were combined into category "Other". This last group consists of women who classified themselves as White, Mestizo, Montubio or Other in Ecuador and Rom, Raizal of the Archipelago of San Andrés and Providencia, Palenquero of San Basilio and none of the above in Colombia.
} 
In both countries, in the youngest and the oldest cohort, the lowest educational stratum is composed of indigenous women to the greatest extent, as compared to any other educational group. In Ecuador, the percentage of women with up to completed primary education who are indigenous increased from around 10 to almost 14; in Colombia, it increased from around 3 to 8 . Given that indigenous women in both of the cohorts constitute around $7 \%$ and $3 \%$ of the female population in Ecuador and Colombia, respectively, this means that the lowest educated population stratum is increasingly composed of women who belong to indigenous groups. Since indigenous populations in the region are overrepresented in the lowest income strata (ECLAC 2008; World Bank 2015), it is indeed likely that women who do not go beyond primary school in the youngest cohorts belong increasingly to the lowest socioeconomic group. At the same time, within the group of women who enter secondary school (both those who complete and those who do not complete it) there occurred an increase across cohorts in the percentage of women who are indigenous. This suggests that it is likely that an increasing share of relatively poorer women are entering secondary school.

Two additional issues need to be considered when interpreting the results of the analysis conducted in this study for Peru. First, for that country for women who entered higher education there was no information about the number of years completed at that level. It could only be identified whether these women completed or did not complete the level Superior. This has no consequences for the analysis conducted using the absolute education level classification, but has to be considered in the analysis that uses the relative classification. Second, there is a substantial level of missing values for the variable describing the age at first birth in Peru. Additional analysis (not shown) revealed that this is likely due to the misclassification of nulliparous women as having a missing value on the variable describing the number of children ever born, among whom the information about the age of first birth was not collected. This suggest that, generally, the quality of fertility information in the census of Peru is likely to be the lowest of all of the three countries. How these two issues are handled, as well as description of additional robustness checks conducted to ensure that these aspects do not affect the main analyses conducted in this study, is presented in the Appendix.

\section{Results}

Figure 3 shows the changes in educational composition across four chosen cohorts. An increasing percentage of women has been entering and completing more advanced levels, in particular secondary school. While the percentage of women in the lowest educational category more than halved, the highest educational level completion almost doubled. Moreover, the drop-out from secondary 


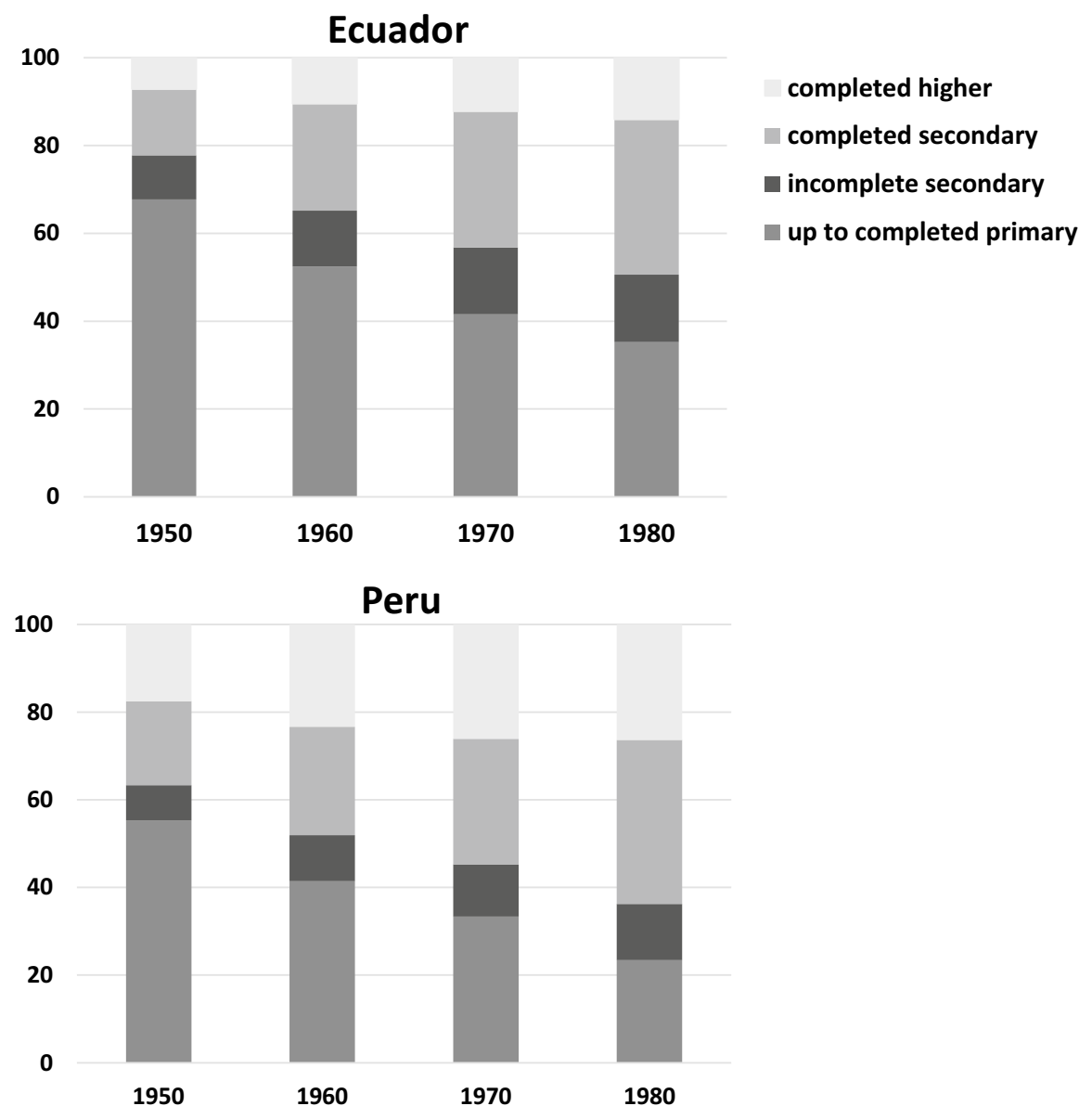

\section{Colombia}

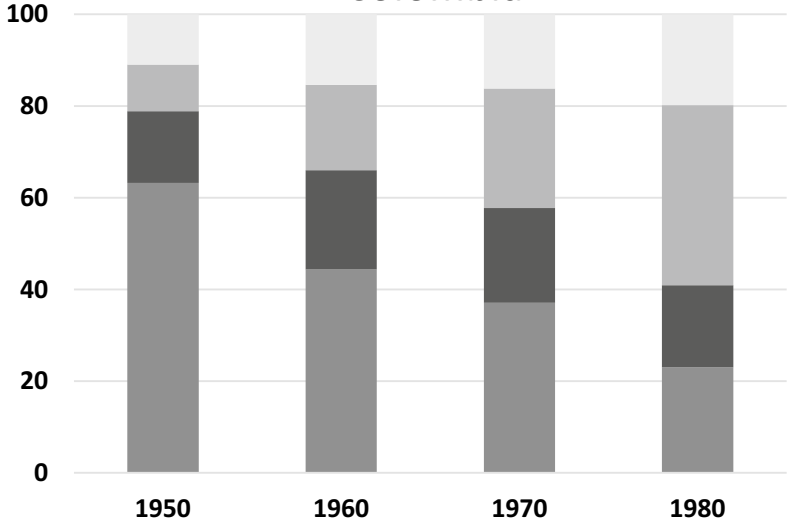

Fig. 3 Educational composition of four selected birth cohorts: 1950, 1960, 1970 and 1980, Ecuador, Peru, and Colombia (\% of the total female population by education level). Source Author's calculations from Population and Housing Censuses Colombia 2005, Peru 2007, Ecuador 2010 

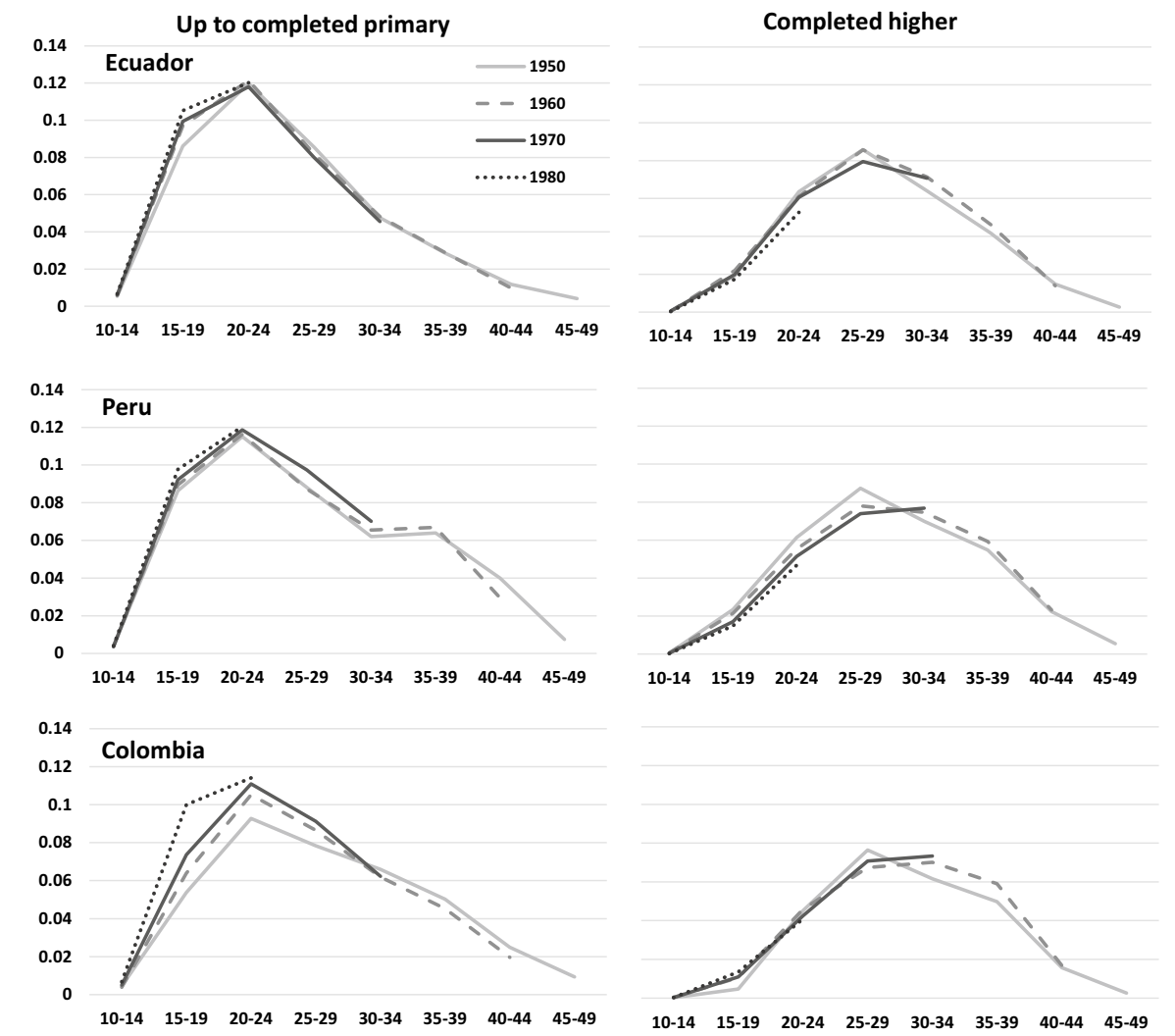

Fig. 4 First-birth age-specific rates, birth cohorts 1950-1980, the lowest and the highest level of educational attainment, Ecuador, Peru, and Colombia. Source Author's calculations from Population and Housing Censuses Colombia 2005, Peru 2007, Ecuador 2010

educational institutions increased. In Ecuador and Peru, there was a change by more than $50 \%$ in the percentage of women who entered, but completed fewer years than necessary to finish secondary school between the 1950 and 1980 cohort. In Colombia, the increase was less pronounced but the level of secondary school drop-out in the youngest cohort was the highest of all three countries.

Figure 4 shows a stark contrast between the first-birth age-specific profiles of women with the lowest and the highest educational level. A common feature of all of the countries has been an increase in the rates of first birth in the age group 15-19 among women with up to completed primary education. The rejuvenation of the first-birth pattern was most pronounced in Colombia: the rate of first birth in the age group 15-19 doubled between the 1950 and 1980 cohort. The schedule for women with a low level of education in Peru shows a plateauing of the first birth rate above the age of 30 . It is possible that the lower quality of fertility data for Peru, as described in the previous section and the Appendix, could be contributing to that pattern. 

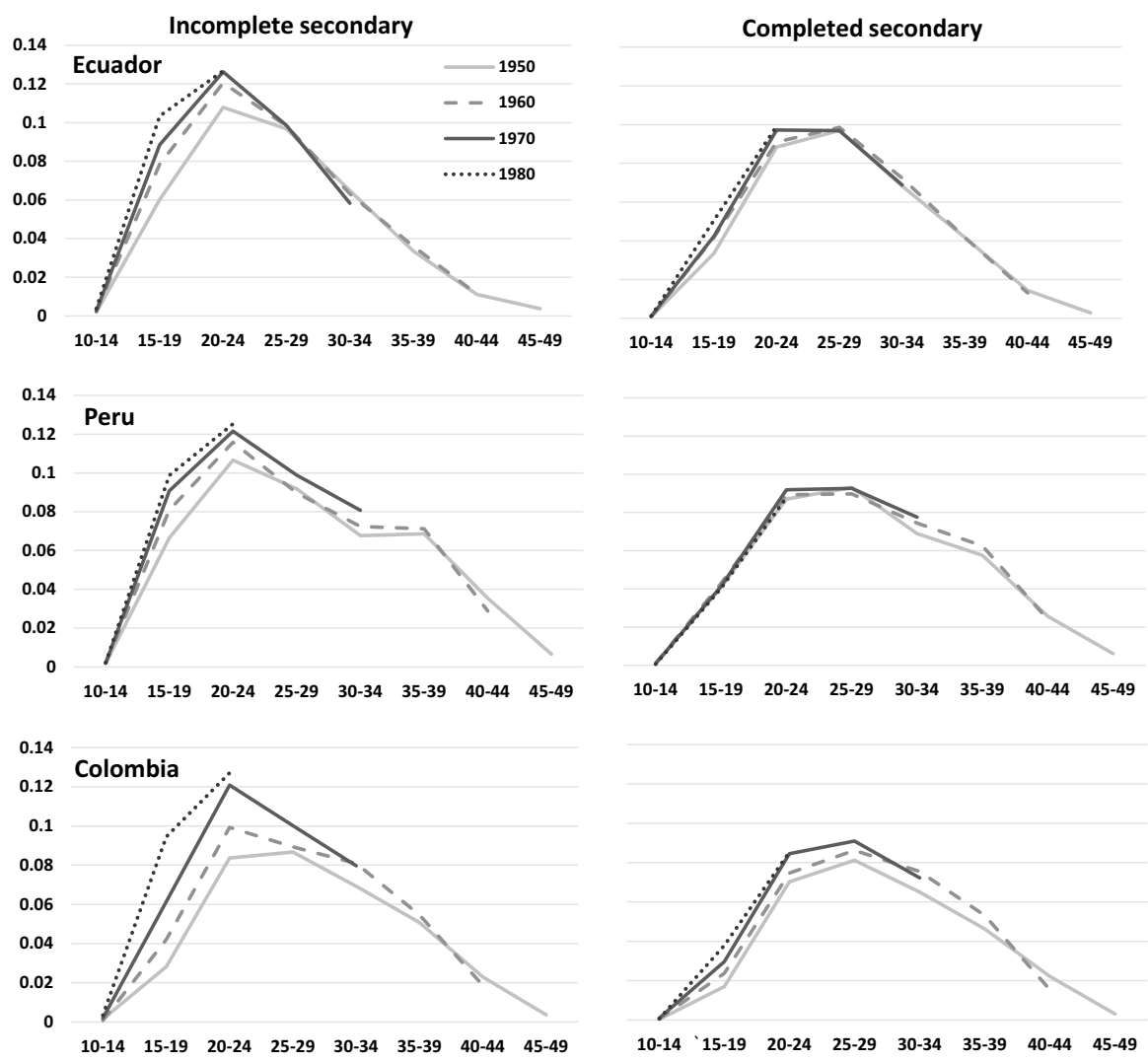

Fig. 5 First-birth age-specific rates, birth cohorts 1950-1980, middle educational attainment groups, Ecuador, Peru, and Colombia. Source Author's calculations from Population and Housing Censuses Colombia 2005, Peru 2007, Ecuador 2010

The first births for women who completed university remained concentrated at older ages. The peak of the schedules in Peru and Colombia has been slowly shifting from the age group 25-29 to 30-34, while in Ecuador it remained in the age group 25-29. In all countries, the rate of first birth decreased during women's $20 \mathrm{~s}$. One the other hand, the rate of first birth above the age of 30 started to increase across cohorts. Consequently, the first-birth schedules started to shift to older ages in all countries. These results point to the emerging postponement of motherhood among highly educated women, visible already when comparing the 1950 and the 1960 cohort.

Figure 5 shows that in all three countries the first-birth age-specific schedules differed vastly also between women with intermediate levels of schooling: those who entered secondary school and completed it and those who did not complete it. Women who dropped out of secondary school substantially advanced transition to motherhood. The change in the first-birth schedules among women who completed secondary school has been much less pronounced. There does not seem to be 

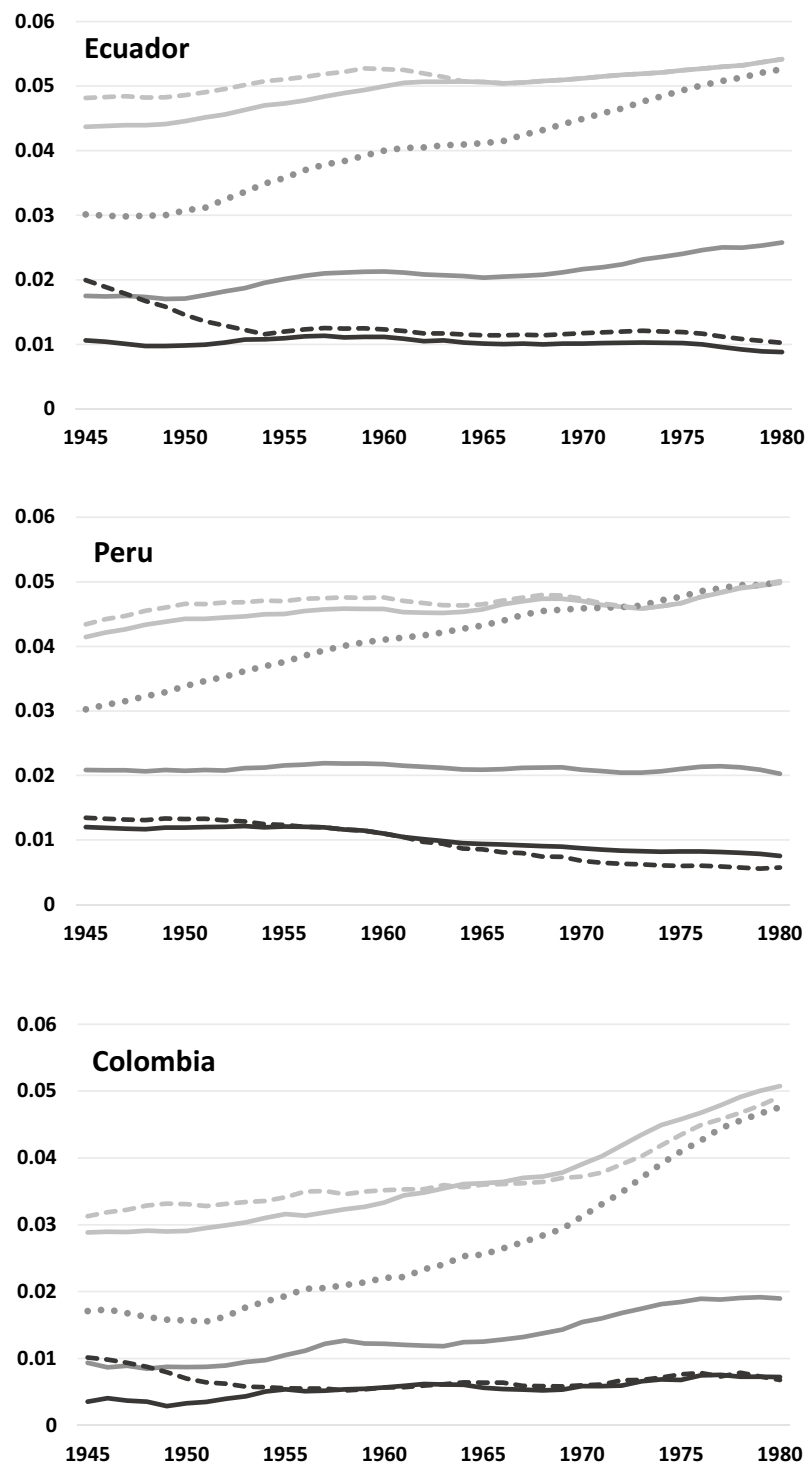

Fig. 6 First-birth rates, age group 10-19, cohorts 1945-1980, by educational attainment and educational quartiles (first Q1 and fourth Q4 quartile), Ecuador, Peru, and Colombia. Source Author's calculations from Population and Housing Censuses Colombia 2005, Peru 2007, Ecuador 2010

a consistent pattern of change within that educational stratum across the three countries, an aspect discussed further below.

To examine in detail the changing disparities in the timing of motherhood between the educational groups throughout the fertility transition, I show the trends in the firstbirth rates in three age intervals: 10-19, 20-29, and 30-39 (Figs. 6, 7, and 8, respectively). I present these results for cohorts of women born between 1945 and 1980, 

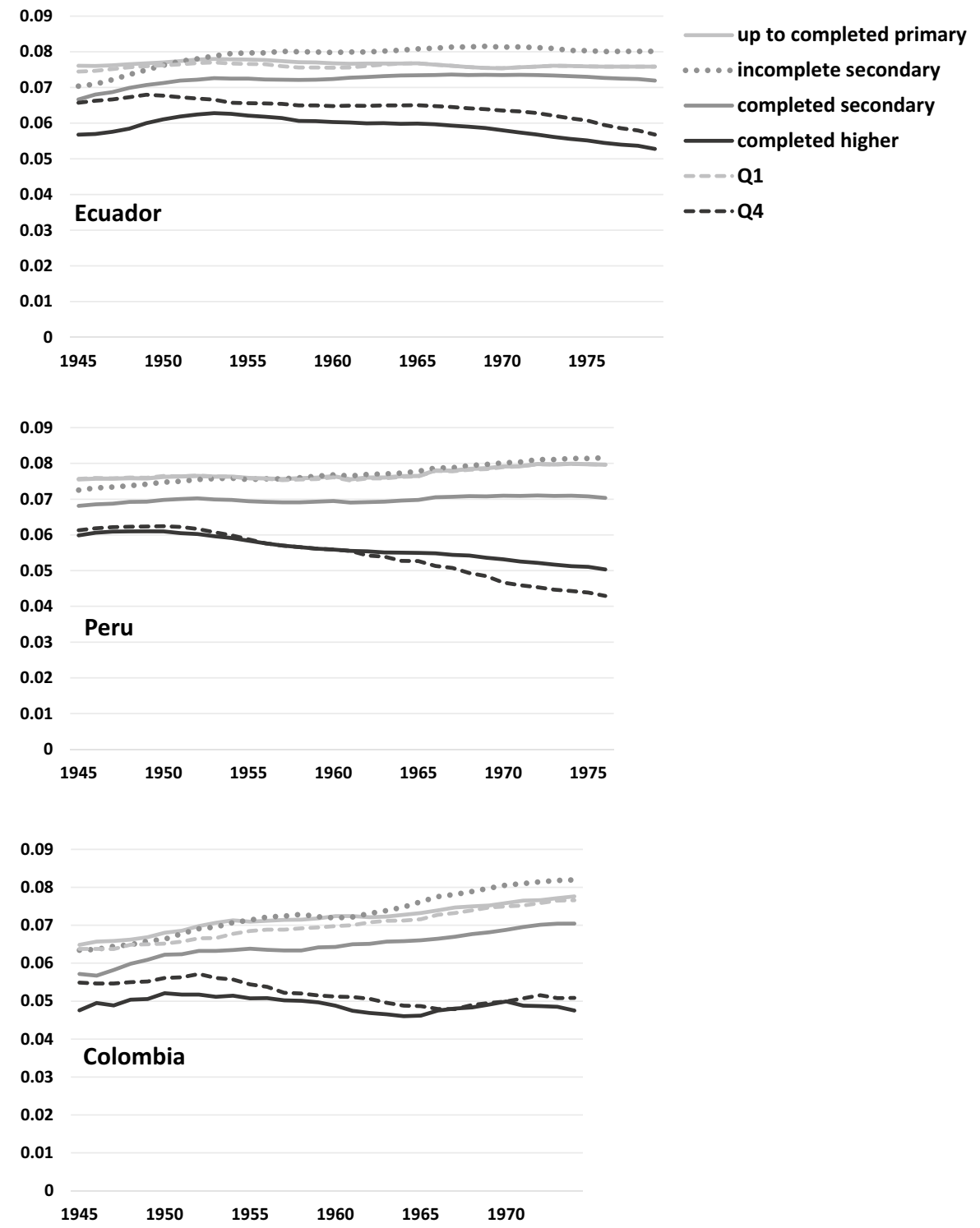

Fig. 7 First-birth rates, age group 20-29, cohorts 1945-1979, by educational attainment and educational quartiles (first Q1 and fourth Q4 quartile), Ecuador, Peru, and Colombia. Source Author's calculations from Population and Housing Censuses Colombia 2005, Peru 2007, Ecuador 2010

for which these rates can be calculated. I show the estimates for the four educational groups representing educational attainment (solid lines). In each figure, I also include the first-birth rates for the lowest and the highest educational quartiles (dashed lines).

The increase in very early motherhood (below age 20) was mainly associated with low levels of education (Fig. 6). However, in all countries it was among 

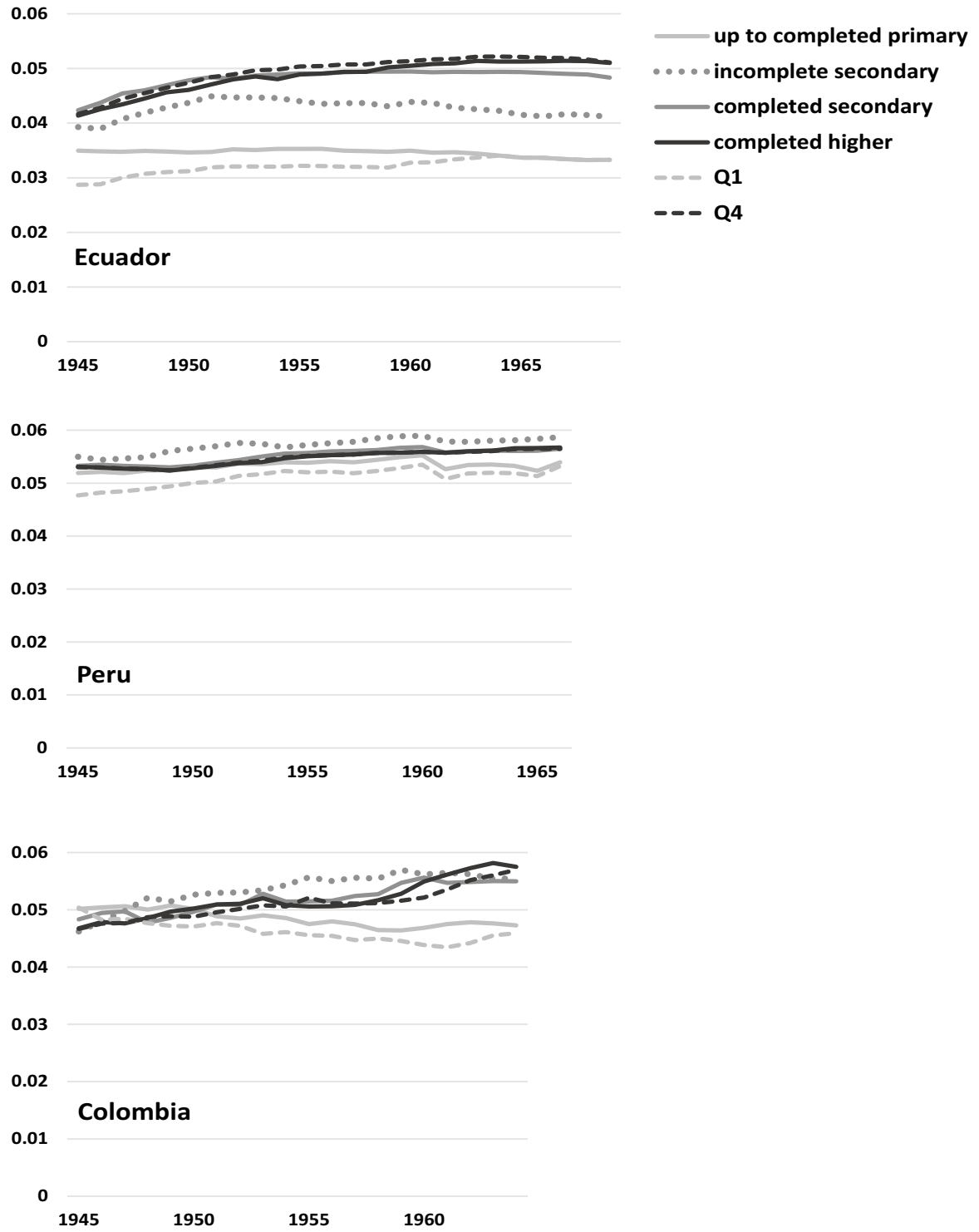

Fig. 8 First-birth rates, age group 30-39, cohorts 1945-1969, by educational attainment and educational quartiles (first Q1 and fourth Q4 quartile), Ecuador, Peru, and Colombia. Source Author's calculations from Population and Housing Censuses Colombia 2005, Peru 2007, Ecuador 2010

women who dropped out of secondary school that the advancement of motherhood was most pronounced. In Ecuador and Colombia teenage childbearing increased also among women who completed secondary school. Nevertheless, the teenage first birth rate among them have been much lower than among those who dropped out of secondary school. Moreover, in all countries the difference in the 
rate of early first birth increased substantially between women who completed and did not complete secondary school. This means that women who enter secondary school have been becoming an increasingly diverse group. Furthermore, the results suggest that the association between secondary school drop-out and teenage pregnancy considerably strengthened across cohorts. Among the youngest cohorts, abandoning secondary school is much more likely to be associated with teenage motherhood than it was in the past. At the same time, a convergence of the first-birth rates occurred between women with up to primary education and women who entered but did not complete secondary school. The difference in the rates of first birth below the age of 20 between the two lowest educational groups, while substantial for the oldest cohorts, virtually disappeared for the youngest ones.

In all countries, the difference in the rates of very early first birth increased also between women who completed secondary school only and those who completed higher education. In Ecuador and Colombia, this was due to the advancement of motherhood among women who completed secondary school. In Peru, this is also observed due to the decrease in the rate of adolescent first births among women with university education. These changes suggest that women who completed secondary school have not been following the behavior of women who completed university throughout the fertility transition.

The results of the trends in the first-birth rates of women in the bottom (Q1) and the top (Q4) quartiles cast light on the changing disparities between the least and the most educated. The increasing difference in the rate of first birth between these two population groups below the age of 20 is clearly visible. The increase in the first birth rate is only slightly less pronounced among women in the bottom of the educational distribution, as compared to women in the lowest, fixed educational attainment group. The direction of the difference between the educational classifications is as expected, but the magnitude of this difference is small. For Peru and Colombia, the difference is only subtle. This provides evidence that women in the least educated stratum of the population have been advancing transition to motherhood across cohorts in the three countries and that was unlikely driven by the fact they have become an increasingly select group. Moreover, the results reveal that among the top educated $25 \%$ of the population, the teenage first birth rates decreased between the oldest and the youngest cohort in all three countries. Consequently, the extent of the divergence between the lowest and the highest educated in very early motherhood is similar when the analysis is conducted using the two educational classifications. These findings suggest that the first-birth timing has been increasingly varying between these two populations groups, and that the changing educational composition of cohorts had a limited contribution to that pattern.

The increasing differentials in the rates of first birth are also observed in the age interval 20-29, with clearly visible widening gaps between the educational groups in all countries (Fig. 7). The rate of first birth among women with completed higher education is markedly lower than among the rest of the subgroups. This means that 
these women had the lowest progression rates to motherhood out of all educational strata not only in teenage years, but also in their $20 \mathrm{~s}$. Women with the highest educational attainment were the only ones among whom there is an evidence of a decrease in the rate of first birth at that age, starting from cohorts born around the 1950s. The relative educational level classification shows a clear decrease in the rate of first birth among the top educated women across cohorts in the three countries. The reduction of the rate of first birth signals that highly educated women have been retreating from childbearing during their $20 \mathrm{~s}$. Consequently, the disparities widened between women with the highest levels of schooling and all other groups in the three countries.

The decrease in the motherhood rate below the age of 30 among the most educated women might mean lower levels of childbearing across cohorts or a shift of motherhood to older ages. Looking at whether the rates of first birth were increasing or not above the age of 30 gives further insights into these processes (Fig. 8). These trends encompass only women born up to the years 1969, 1966, and 1964 in Ecuador, Peru, and Colombia, respectively, since these are cohorts that reached the age of 39 at the time of the census.

The rate of first birth at older ages between the oldest and the youngest cohorts increased to the largest extent among women with completed higher education in Ecuador and Colombia; a smaller change occurred in Peru. This emerging trend and the decrease in the rate of first birth below the age of 30 suggests the beginnings of realization of postponed births among women with the highest levels of schooling. This process has been more clearly visible from the changes in the first-birth agespecific schedules shown in Fig. 4.

An increase in the rate of first birth above age 30 occurred also among women who completed secondary education. This happened in spite of a rising or a stable rate of first birth among them at younger ages. It is likely that due to the substantial increase in the percentage of women who complete secondary school, this subgroup of women became more diverse. This might be reflected in the elevated rate of first birth among them both at the younger and older ages. This is a plausible explanation as the group of women who completed secondary school in this study encompasses also those who dropped out of university. Additional analysis (not shown) suggests that, although resembling more the pattern of motherhood timing of women who completed secondary school only, as compared to those who completed university, those who entered but did not complete higher education transition to first birth slightly later than those who finished their education at the secondary level.

The trends in the rate of first birth in the age interval 30-39 for women in the two lowest educational groups are least consistent across the three countries, but they are relatively more stable compared to the two highest educational strata. In Ecuador and Colombia, these processes resulted in slightly widening differences in the rate of first birth at older ages between women who completed at least secondary school and those who completed up to primary school. This change is observed when looking both at the relative and absolute level classifications, but the pattern is much less consistent than in the younger age groups. Very little change in these disparities is observed in Peru. Again, the likely poorer quality of fertility data for Peru should be kept in mind when looking at the presented patterns. This is particularly important 
for the interpretation of the disparities at older ages given the previously identified plateauing of the first-birth rates above the age of 30 among women with lower levels of education. In general, the changes in the rates and the degree of the divergence in the pattern of first birth in the age group 30-39 have been the smallest of all age intervals. This is related to the fact that with the available data the rates cannot be yet calculated for the more recently born women, which does not allow for a more detailed examination of these trends.

\section{Discussion}

This paper examined the long-term cohort trends in the educational differences in the age at first birth for Ecuador, Peru, and Colombia. The existing disparities in the three countries are a result of a long process of divergence in reproductive behavior between the educational groups throughout the fertility transition. The increasing differences in the rates of first birth are observed both at the younger and older ages.

The first main finding from this study is that disparities in the timing of transition to motherhood increased between the lowest and the highest educated women not only due to the earlier transition to first birth among the lowest educated, but also due to emerging first birth postponement among women who completed university. The latter process is mainly visible in the reductions in rates of first birth during women's $20 \mathrm{~s}$, but the evidence of increases in the rates of first birth above the age of 30 is starting to emerge. The first-birth age-specific schedules among women who completed university have started to shift to older ages, interestingly, already when comparing women born around the 1950s and 1960s. These findings cast new light on the patterns of motherhood timing in the Andean region and highlight two aspects. First, important insights about the changes in the timing of childbearing in that context can be gained from looking at the evolution of the first-birth agespecific schedules. Second, the analysis of rates of transition to first birth in teenage years only is no longer sufficient to understand fully the changes in the timing of motherhood in these countries.

The results also cast light on one of the plausible factors behind the increasing disparities between the lowest and the highest educated women. The analyses reveal that the changing educational composition of the population was unlikely to be behind this divergence. When using a measure that takes into account changing educational composition of the cohorts, the magnitude of the disparities was similarly pronounced in the three countries. In particular, the analyses show that the $25 \%$ of least educated women was transitioning to motherhood earlier over time. Contrary to expectations and conclusions of the previous studies on the topic (Esteve and Florez-Paredes 2018), increasing intensity of early childbearing among women with the lowest levels of schooling was attenuated little when the relative and the absolute educational classifications were compared. This suggests that teenage firstbirth increases among the least educated women have been driven to only a small extent, if any, by the fact that they have become an adversely select group. This means that women in the lowest socioeconomic stratum have continued to fail to 
benefit from the expansion of the educational systems or increasing access to contraception as compared to women in the higher socioeconomic groups.

Moreover, the differences in the rates of first birth increased also between the highest educated women and women who completed secondary school only. This change is visible in the different trajectories of the first-birth rates below both the age of 20 and 30. Previous research suggested that the meaning of completion of secondary school changed over time in Latin America and obtaining a secondary school degree might not be translating into enhanced employment opportunities (Rodríguez Vignoli and Cavenaghi 2013). The finding from this study that women who completed secondary education have not been following the behavior of women who completed university in the three countries adds to that body of research. These results could point to the importance of the decreasing power of obtaining a secondary school degree in ensuring employment due to the substantial expansion of secondary schooling observed in the last decades. The evidence for Latin American countries shows that the wages of secondary school graduates decreased relative to those who obtain lower levels of education (Manacorda et al. 2010). Currently, it is the completion of higher education that increases most the rates of return in terms of income in the labor market (ECLAC 2010; Hopenhayn 2012). The changing differences in the employment opportunities between the highly educated and all other population groups due to educational expansion are a plausible explanation for the identified increasing first-birth disparities.

The second main finding from this study relates to the variation in the first-birth timing among women with intermediate levels of schooling, providing a new dimension to understanding of teenage first-birth increases in the Andean region. Consistently across the three countries, the intensity of very early first birth increased to the largest extent among women who dropped out of secondary school. The disparities in the rates of first birth in adolescence increased substantially between those who dropped out of and those who completed secondary school. This process could have been driven by the increasing share of relatively poorer girls entering secondary school over time who enrol, but do not complete their education. This can be inferred from the convergence of the rates of first birth between those who drop out of secondary school and those who finish their education at the primary level. Such interpretation can also be seen as in line with the changes in the composition of the educational groups across cohorts presented in "Data and methods" section, which suggested an increase in the percentage of women from lower socioeconomic strata among those who enter secondary school.

The knowledge about whether teenage pregnancies follow or precede school abandonment would be vital to make conclusions about the reasons behind the vast increase in the rates of first births among women who dropped out of school. Although this aspect cannot be studied here, a few existing studies about the sequencing of these events in the region can shed light on the factors behind this increase. In Colombia, among young women from poorer backgrounds pregnancy was found to mainly follow school abandonment. Moreover, school withdrawal before becoming pregnant was more prevalent among teenagers from lower socioeconomic strata (Flórez and Soto 2007). The authors argued that it was likely that these pregnancies largely were not unintended and were driven by the same factors 
as school drop-out, namely disadvantage and poverty. Moreover, the study of Näslund-Hadley and Binstock (2011) showed that one quarter of young women they interviewed in Peru and half in Paraguay dropped out before becoming pregnant and this was due to lack of interest in continuing education or a need to enter the labor market. Those who were still in school at the time of pregnancy, decided to leave due to their already poor academic performance, low quality of schooling and low expectations regarding the benefits of continuing education. Their qualitative investigation did not support the common assumption that unintended pregnancy was a leading factor for school drop-out among young mothers who discontinued education. Rather, it was the educational underachievement that preceded adolescent childbearing.

The levels of unintended motherhood among teenagers are high and have increased in the Andean region (Measure DHS 2018; Rodríguez Vignoli 2017). This factor could be behind the steep rise in the rates of first birth among secondary school drop-outs identified in this study. Nevertheless, given the evidence from the above presented studies, it is likely that the observed rise in teenage first births was only to some extent driven by the increasing levels of unintended childbearing that lead to school abandonment. The limited opportunities determining both school withdrawal and subsequent adolescent motherhood are an equally plausible explanation for that pattern. Such reasoning is in line with research attributing the high level of teenage fertility in Latin America more broadly to high levels of social and economic inequalities (Azevedo et al. 2012). As described in "Context of the Andean region: Ecuador, Peru and Colombia" section, such inequalities can be reflected in the inequalities in the educational opportunities and in students' school performance, which are related to school drop-out. Although children from more disadvantaged groups have been increasingly entering secondary school across generations, the quality of the institutions they attend and their school completion rates are lower than among those in the more advantaged groups (ECLAC 2002, 2007, 2010). Quality of school can influence educational aspirations, perceived returns to education, prospects of attending university and consequently students decisions about whether to complete school (Azevedo et al. 2012; ECLAC 2010; Kattan and Székely 2015). These in turn can determine young women's opportunities, for example on the labor market, which have a potential to influence their motivation to avoid early motherhood. The disparities in access to quality educational opportunities as well as substantial levels of social segregation of schools are known barriers, which contribute to high levels of school drop-out in the region. They could also be one of the factors behind the strengthening association between school abandonment and the early pregnancy alongside educational expansion identified in this study.

Although causality between early childbearing and school drop-out cannot be established in this study, the fact that the association between school abandonment and early pregnancy has strengthened across cohorts suggest that the factors behind the teenage fertility increase in the region could be closely connected with the factors behind the high levels of secondary school drop-out. From the policy perspectives, the results of this paper suggest that the interventions to reduce school dropout could potentially be one of the channels to address to some extent the high levels of adolescent birth rates. Tackling barriers to secondary school completion, such as 
disparities between the socioeconomic strata in terms of opportunities to receive quality education and school segregation could be important in the three countries. Moreover, school drop-out and teenage motherhood are likely to have similar root causes. Therefore, further identifying the reasons behind the school drop-out as a strategy to understand better adolescent motherhood in the region could be considered as one of the policy avenues.

Overall, this study shows that the use of census data can improve understanding of the long-term developments in the timing of motherhood. Although not without limitations, the retrospective birth history data from censuses are a valuable source of information. The census data allow for a detailed study of the long-terms trends disaggregated by various measure of education level, but due to the limited information about other aspects such as timing of union formation or initiation of sexual activity, they cannot be explored to study other aspects closely related to the timing of first birth. Nevertheless, in the context of the emergent motherhood postponement in Latin America, there is likely going to be a growing need to study this aspect of change in reproductive behavior. Census data are important for the estimation of the first-birth age-specific schedules in general, and in particular, among those subpopulations which are likely to be postponing motherhood. Therefore, this source of information should be considered as complementary to the use of conventionally exploited for the Andean region surveys. Moreover, census data constitute a valuable alternative for countries where recent DHS data are not available. In light on the upcoming 2020 round of censuses in Latin America, statistical offices should sustain the efforts to collect information about age at first birth in censuses.

Acknowledgements I thank Tiziana Leone and Mikko Myrskylä for their helpful comments and suggestions. I am also grateful to Piedad Urdinola for her help in producing this work. The data from the Population and Housing Censuses were obtained from the statistical offices of the respective countries. I gratefully acknowledge Departamento Administrativo Nacional de Estadística (DANE), Instituto Nacional de Estadística e Informática (INEI) and Instituto Nacional de Estadística y Censos (INEC) for making data available for this project. The author alone is responsible for the data analysis and the interpretation of the results. This research was funded by the UK Economic and Social Research Council Doctoral Studentship of the London School of Economics and Political Science.

Open Access This article is distributed under the terms of the Creative Commons Attribution 4.0 International License (http://creativecommons.org/licenses/by/4.0/), which permits unrestricted use, distribution, and reproduction in any medium, provided you give appropriate credit to the original author(s) and the source, provide a link to the Creative Commons license, and indicate if changes were made.

\section{Appendix}

Two additional issues need to be considered when interpreting the results of the analysis conducted in this study for Peru. First, for that country for women who entered higher education there was no information about the number of years completed at that level. It could only be identified whether these women completed or did not complete the level Superior. This has no consequences for the analysis conducted using the absolute education level classification, but has to be considered in the analysis that 
uses the relative classification. For women who entered, but did not complete higher education, I assumed that they completed only 1 year at that level. I make this assumption on the basis of the evidence that the higher education drop-out in Latin America is concentrated at the beginning of the college career (Ferreyra et al. 2017). In order to check whether the quartiles obtained from the census are an accurate depiction of the educational distribution across cohorts, I compared them with the quartiles calculated from the available DHSs for Peru. The similarity of the results gives confidence that the quartiles calculated from the census approximate well the measure of interest.

Second, there is a high level of missing values for the variable describing the age at first birth in Peru. A thorough examination of this issue revealed that the information about the age at first birth in all countries in the census has been recorded only for women with a valid response to the question about the number of children ever born (CEB). For Colombia and Ecuador, the missingness level for the variable describing age at first birth was small (3.3\% in Ecuador and $4.5 \%$ in Colombia). Moreover, there were no substantial differences in the distribution of the missing values for that variable and the CEB variable, depending on women's year of birth and education level. I consequently excluded women for whom the information about the age at first birth was not recorded. For Peru, the problem was more pronounced (11.7\% responses missing). For that country, I assumed that women for whom the response to the question about the CEB was missing had zero children, for the following reasons. A commonly observed problem in the censuses regarding the CEB information is the misclassification of childless women as having a missing value on that variable (El-Badry 1961). An in-depth examination of the profile of women with missing values on CEB in Peru showed that it was very similar to the profile of nulliparous women. Second, I compared the percentage of childless women by year of birth in the 2007 census with the 2007/8 DHS (INEI 2008). The percentage of nulliparous women in the census was substantially lower than in the DHS. When women with missing values on CEB variable in the census were assumed to have 0 children, the percentage of childless women in DHS and census was very similar.

As a sensitivity check, I conducted an additional set of analyses that are the main purpose of this paper for Peru. Instead of assuming that women with missing values on CEB had 0 children, I excluded them from the analysis. The main conclusions of interest in this study regarding the changes in the disparities in the age at first birth by education level remained unchanged (not shown). Nevertheless, the poorer data quality should be kept in mind when interpreting the fertility patterns for that country. First, the applied assumption might have resulted in the overestimation of the number of childless women, as some women with missing values were probably not nulliparous. It is likely that the first-birth rates will be more sensitive to that problem the higher the age group considered. This is because the denominator of the firstbirth rate will be influenced by that assumption to an increasing extent, the smaller the number of women who are still childless becomes. Second, even when women with missing values are assumed to have 0 children, the information about the age at first birth remains missing for $6 \%$ of women. 


\section{References}

Azevedo, J. P., Favara, M., Haddock, S. E., Lopez-Calva, L. F., Müller, M., \& Perova, E. (2012). Teenage pregnancy and opportunities in Latin America and the Caribbean. Washington, DC: World Bank Group.

Bassi, M., Busso, M., \& Muñoz, J. S. (2015). Enrollment, graduation, and dropout rates in Latin America: Is the glass half empty or half full? Economía, 16(1), 113, 115-156.

Batyra, E. (2016). Fertility and the changing pattern of the timing of childbearing in Colombia. Demographic Research, 35(46), 1343-1372.

Bound, J., Geronimus, A. T., Rodriguez, J. M., \& Waidmann, T. A. (2015). Measuring recent apparent declines in longevity: The role of increasing educational attainment. Health Affairs, 34(12), 2167-2173.

Bozon, M., Gayet, C., \& Barrientos, J. (2009). A life course approach to patterns and trends in modern Latin American sexual behavior. Journal of Acquired Immune Deficiency Syndromes (1999), 51(Suppl 1), S4-S12.

Carlson, B.A. (2001). Education and the labour market in Latin America: Why measurement is important and what it tells us about policies, reforms and performance. Serie desarrollo productiveo (Vol. 114). Santiago: United Nations.

Castro-Martín, T., \& Juarez, F. (1995). The impact of women's education on fertility in Latin America: Searching for explanations. International Family Planning Perspectives, 21(2), 52-57+80.

Chackiel, J., \& Schkolnik, S. (1996). Latin America: Overwiev of the fertility transition. In J. M. Guzmán, S. Singh, G. Rodriguez, \& E. A. Pantelides (Eds.), The fertility transition in Latin America (pp. 1950-1990). Oxford: Clarendon Press.

Cornia, G. A. (2014). Falling inequality in Latin America: Policy changes and lessons. Oxford: Oxford University Press.

Daude, C. (2013). Education and social mobility in Latin America. LasaForum, XLIV(2), 7-9.

Davis, J., Bilsborrow, R., \& Gray, C. (2015). Delayed fertility transition among indigenous women in the Ecuadorian Amazon. International Perspectives on Sexual and Reproductive Health, 41(1), 1-10.

ECLAC. (2002). Social panorama of Latin America 2001-2002. Santiago: United Nations.

ECLAC. (2005). Social panorama of Latin America 2005. Santiago: United Nations.

ECLAC. (2007). Social panorama of Latin America 2007. Santiago: United Nations.

ECLAC. (2008). Social panorama of Latin America 2008. Santiago: United Nations.

ECLAC. (2010). Social panorama of Latin America 2010. Santiago: United Nations.

ECLAC. (2011). Social panorama of Latin America 2011. Santiago: United Nations.

El-Badry, M. (1961). Failure of enumerators to make entries of zero: Errors in recording childless cases in population censuses. Journal of the American Statistical Association, 56(296), 909-924.

Esteve, A., \& Florez-Paredes, E. (2014). Edad a la primera unión y al primer hijo en América Latina: estabilidad en cohortes más educadas. Notas de Población, 99, 39-65.

Esteve, A., \& Florez-Paredes, E. (2018). The stability paradox: Why expansion of women's education has not delayed early union formation or childbearing in Latin America. Studies in Family Planning, 49(2), 127-142.

Ferreyra, M. M., Avitabile, C., Botero Allvarez, J., Haimovich Paz, F., \& Urzúa, S. (2017). At a crossroads: Higher education in Latin America and the Caribbean. Washington, DC: World Bank Group.

Flórez, C. E. (2005). Factores socioeconómicos y contextuales que determinan la actividad reproductiva de las adolescentes en Colombia. Revista Panamericana de Salud Pública, 18(6), 388-402.

Flórez, C. E., \& Soto, E. V. (2007). Fecundidad adolescente y desigualdad en Colombia. Notas de Población, 83, 41-74.

Gaviria, A. (2000). Decisiones: sexo y embarazo entre las jóvenes colombianas. Coyuntura Social, 84, 83-95.

Heaton, T. B., \& Forste, R. (2009). Education as policy: the impact of education on marriage, contraception, and fertility in Colombia, Peru, and Bolivia. Social Biology, 45, 194-213.

Hopenhayn, M. (2012). Education, life cycle and social mobility: A Latin American perspective. Expert Paper No. 2012/2. New York: United Nations.

INEI. (2008). Encuesta Demografica y de Salud Familiar EDSF 2007/8 Perú. Lima: Instituto Nacional de Estadística e Informática.

Kattan, R. B., \& Székely, M. (2015). Analyzing the dynamics of school dropout in upper secondary education in Latin America. A cohort approach. Policy Research Working Paper 7223. Washington DC: World Bank Group. 
Lima, E. E. C., Zeman, K., Sobotka, T., Nathan, M., \& Castro, R. (2018). The emergence of bimodal fertility profiles in Latin America. Population and Development Review, 44(4), 723-743.

Manacorda, M., Sanchez-Paramo, C., \& Schady, N. (2010). Changes in returns to education in Latin America: the role of demand and supply skills. ILR Review, 63(2), 307-326.

Measure, D. H. S. (2018). STATcompiler [electronic resource]. Calverton, MD: ICF.

Mills, M., Rindfuss, R. R., McDonald, P., \& te Velde, E. (2011). Why do people postpone parenthood? Reasons and social policy incentives. Human Reproduction Update, 17(6), 848-860.

Miranda-Ribeiro, A., \& Garcia, R. A. (2013). Transition or transitions? Analyzing the fertility decline in Brazil in the light of educational levels. Revista Latinoamericana de Población, 7(13), 91-106.

Murillo, F. J., \& Martínez-Garrido, C. (2017). Estimación de la magnitud de la segregación escolar en America Latina. Revista Internacional de Investigación en Educación, 9(19), 1-30.

Näslund-Hadley, E., \& Binstock, G. (2011). El Fracaso Educativo: Embarazos Para No Ir a La Clase. Notas Tecnicas IDB-TN-281. Banco Interamericano de Desarollo.

Nathan, M. (2015). La creciente heterogeneidad en la edad al primer hijo en el Uruguay: un analisis de las cohortes de 1951 a 1990. Notas de Población, 100, 35-60.

Rios-Neto, E. L. G., De Miranda-Ribeiro, A., \& De Miranda-Ribeiro, P. (2018). Fertility differentials by education in Brazil: From the conclusion of fertility to the onset of postponement transition. Population and Development Review, 44(3), 489-517.

Rios-Neto, E. L. G., \& Meireles Guimarães, R. R. (2014). The educational gradient of low fertility in Latin America. Paper presented at the Population Association of America Annual Meeting, Boston MA, May 1-3, 2014.

Rodríguez, J. (2013). High adolecent fertility in the context of declining fertility in Latin America. Expert Paper No. 2013/14. New York: United Nations.

Rodríguez Vignoli, J. (2014a). Fecundidad adolescente en América Latina: una actualización. In S. Cavenaghi \& W. Cabella (Eds.), Comportamiento Reproductivo y Fecundidad En Latin America: Una Agenda Inconclusa. Rio de Janeiro: ALAP.

Rodríguez Vignoli, J. (2014b). La Reproducción En La Adolescencia y Sus Desigualdades En América Latina. Santiago de Chile: CEPAL.

Rodríguez Vignoli, J. (2017). Deseabilidad y planificación de la fecundidad adolescente en América Latina y el Caribe: tendencias y patrones emergentes. Notas de Población, 104, 119-144.

Rodríguez Vignoli, J., \& Cavenaghi, S. (2013). Adolescent and youth fertility and social inequality in Latin America and the Caribbean: What role has education played? Genus, $\operatorname{LXX}(1), 1-25$.

Rosero-Bixby, L., Castro-Martín, T., \& Martín-García, T. (2009). Is Latin America starting to retreat from early and universal childbearing? Demographic Research, 20(9), 169-194.

United Nations. (2017). World population prospects. The 2017 revision [electronic resource]. New York: United Nations.

Weinberger, M. B., Lloyd, C., \& Blanc, A. K. (1989). Women's education and fertility: A decade of change in four Latin American countries. International Family Planning Perspectives, 15(1), 4-14+28.

World Bank. (2015). Indigenous Latin America in the twenty-first century. Washington, DC: World Bank Group.

Publisher's Note Springer Nature remains neutral with regard to jurisdictional claims in published maps and institutional affiliations.

\section{Affiliations}

\section{Ewa Batyra ${ }^{1,2}$ (iD}

1 Department of Social Policy, London School of Economics and Political Science, Houghton Street, London WC2A 2AE, UK

2 Population Studies Center, University of Pennsylvania, 3718 Locust Walk, Philadelphia, PA 19104-6298, USA 